\title{
A Structural Simulation System, Part 3: Application with Abaqus
}

\author{
Duan Jin ${ }^{1, a}$, Chen Xiao-ming ${ }^{1}$, Li Yun-gui ${ }^{1}$ \\ ${ }^{1}$ China State Construction Technical Center, Beijing, 101300, PR China \\ a duanjin78@126.com
}

Key words: constitutive model, elemental model, reinforced concrete

Abstract: In this paper, the application with Abaqus for the structural simulation system, an integrated simulation system for building structures, is presented. It is aimed to provide dynamic elastic-plastic analysis for reinforced concrete structures. There are two key points would be emphasized in this paper: (1) the constitutive model for reinforced concrete, including one-dimensional constitutive and two-dimensional constitutive; (2) the elemental model for reinforced concrete components, including frame component, shear wall and slab. Finally, a high-rise building numerical example is provided to demonstrate the capacity of the structural simulation system.

\section{Introduction}

To satisfy the building engineering requirements for high performance simulation, an integrated simulation system for building structures, or ISSS for short, has been presented in the part one of this paper. It is a coalition of the traditional design software and general finite element analysis (FEA) software. Based on this system, the designed models, obtained by traditional design software, such as Pkpm, Yjk etc., could be automatically transformed to corresponding FE models ${ }^{[1-4]}$ and imported into commercial FEA software, such as Abaqus, Ansys etc., to finish the complex FE analysis.

In this paper, the application with Abaqus for the structural simulation system, mentioned above, is presented. It is aimed to provide a dynamic elastic-plastic analysis for the reinforced concrete structures. There are two key points would be emphasized in this paper: (1) the constitutive model for reinforced concrete, including one-dimensional constitutive and two-dimensional constitutive; (2) the elemental model for reinforced concrete components, including reinforced concrete frame component, reinforced concrete shear wall and slab, steel reinforced concrete shear wall and composite slab. Finally a high-rise building numerical example is provided to demonstrate the capacity of the structural simulation system.

\section{Application setting based on Abaqus}

For the structural simulation system, application settings based on Abaqus mainly include the following two part: (1) constitutive model of the reinforced concrete; (2) elemental model of the reinforced concrete.

\section{Constitutive model of reinforced concrete}

The constitutive model of reinforced concrete used in the structural simulation system could be described as following:

One-dimensional component(e.g. beam, column, brace): use the one dimensional confined concrete constitutive model. In other words, the confine effect of concrete resulted from the 
stirrup is taken into account. There are two options to be either selected by the users and they are Mander model ${ }^{[5]}$ option and civil code model ${ }^{[6]}$ option respectively.

Two-dimensional component(e.g. shear wall, slab): use the plain concrete constitutive model. In other words, the confine effect of concrete resulted from the reinforced bar and reinforced steel is ignored. There are two options to be either selected by the users and they are damage plastic model ${ }^{[7]}$ option and civil code model ${ }^{[6]}$ option respectively.

\section{Elemental model of reinforced concrete}

The elemental model of reinforced concrete used in this structural simulation system could be described as following:

Frame components (reinforced concrete and steel reinforced concrete): the separated elemental model is adopted in the structural simulation system. The reinforced bar, steel and concrete use the pipe element, beam element and fiber element respectively. The connection between the different element type is all rigid connection and the bond-slip effect between the steel and concrete is all ignored. The plastic shear of the concrete is also ignored for the sake of simplicity;

* Reinforced shear wall and slab: there are two kinds of element model provided in the structural simulation system. They are rebar-layer laminated shell model and separated shell model respectively. In the former one, the rebar in the shear wall would be equivalent to a rebar layer and together with the concrete to generate laminated shell elements. While in the latter one, the rebar would be modeled as rod elements and the concrete would be modeled as shell elements. The two element types are connected rigidly at element nodes and the bond-slip effect between the rebar and concrete is all ignored. For the concrete shell, the plasticity of the membrane and lateral bending is taken into account and the plasticity of lateral shear is ignored for the sake of simplicity;

* Steel reinforced shear wall and composite slab: the laminated shell element would be adopted to model the steel reinforced shear wall and composite slab. The different laminated layer corresponds to different material type, i.e. steel or concrete. The bond-slip effect between the steel and concrete is all ignored. The plasticity of the membrane and lateral bending is taken into account and the plasticity of lateral shear is ignored for the sake of simplicity.

\section{Numerical examples}

To demonstrate the capacity of the structural simulation system, a high-rise building numerical example is provided in the following. This building structure is modeled in YJK, meshed by the present system and analyzed by ABAQUS.

\section{Description of the model}

The structural model was imported from YJK and transformed into FE model automatically in the system, shown in Figure1. The most noteworthy feature of this structure is the plane irregularity. Intuitively, the connective bands at the central zone of the floor may be the weak zone of this structure.

In the dynamic analysis, the one-dimensional constitutive model for beams, columns and braces uses the civil code model for concrete structures (GB-50010-2010) ${ }^{[6]}$, while the two-dimensional constitutive model for walls and slabs adopts the concrete damaged plasticity model of ABAQUS, seeing Abaqus theory manual ${ }^{[7]}$. The dynamic loads take the seismic wave of America EI Centro (1940.5.18, magnitude is 7 , depth is $10 \mathrm{~km}$ ), whose acceleration history of the first 20 seconds is 
shown in Figure 2.
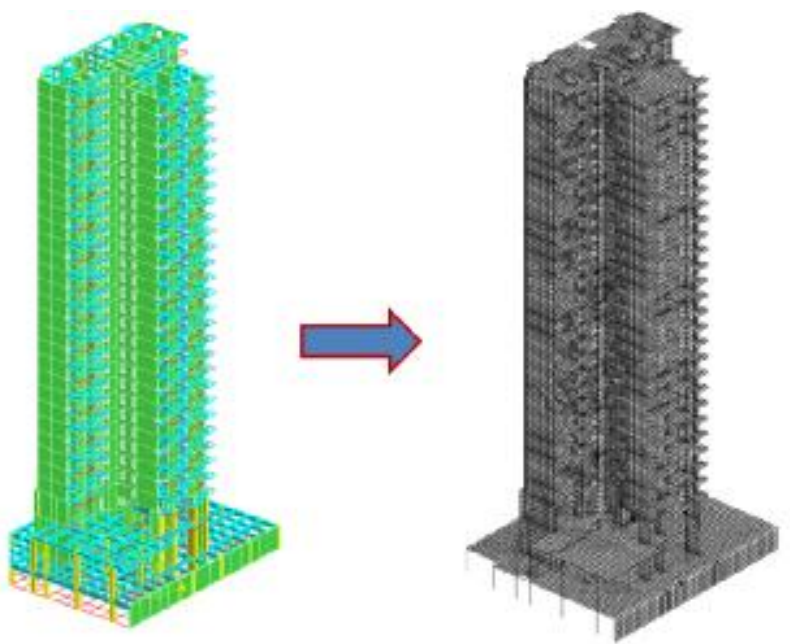

Figure 1 Structural model (YJK) and FE model

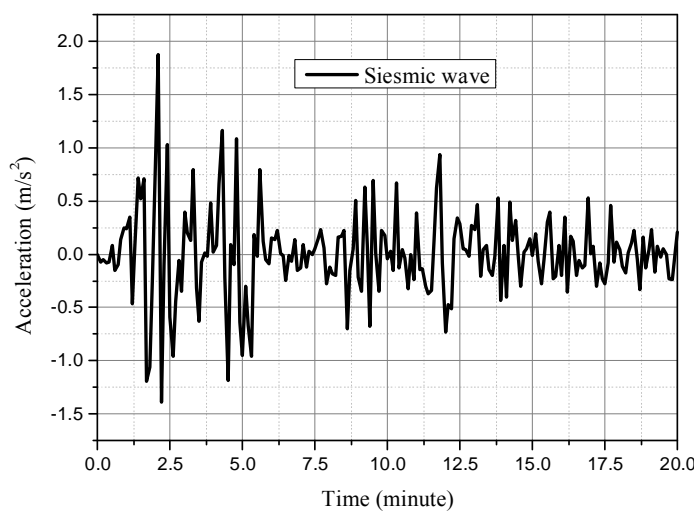

Figure 2 Seismic acceleration (America EI Centro)

\section{Calculated results}

The time history of top displacement is shown in Figure 3 and the base shear is shown in Figure 4 , from which it can be seen that the history shape of the base shear is very similar to that of seismic acceleration, shown in Figure 2. While if they are normalized and plot in the same graph, seeing Figure 5, the differences become conspicuous. The reasons leading to the differences include the elastic wave propagation and the others, which are beyond the scope of this paper.

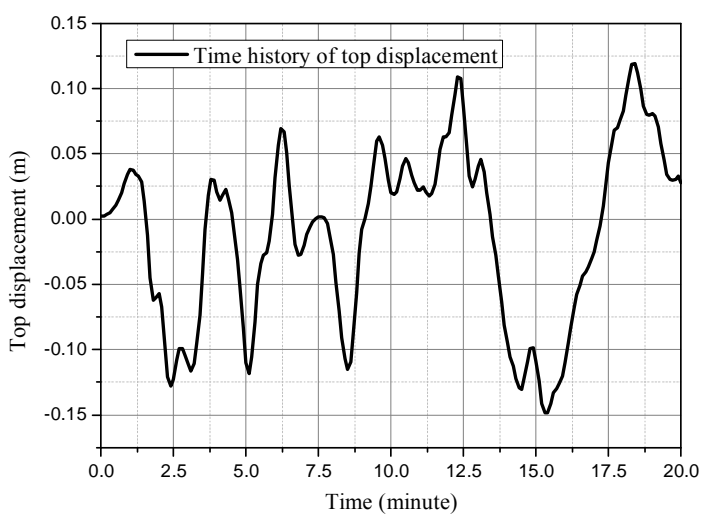

Figure 3 Time history of top displacement

The damage of the structure can be described by the factor of stiffness degradation, which is 
assumed to be functions of plastic strains and the other field variables. This factor indicates the degradation of elastic stiffness. Its value belongs to $0 \sim 1$ interval, in which " 0 " means no damage has occurred while " 1 " means the components have been completely damaged. The stiffness degradation of walls, slabs and frames are shown in Figure 6, Figure 7 and Figure 8 respectively, from which it can be observed easily that the damage concentrates at the connective bands at the central zone of the floor, which is identical with the prediction mentioned early.

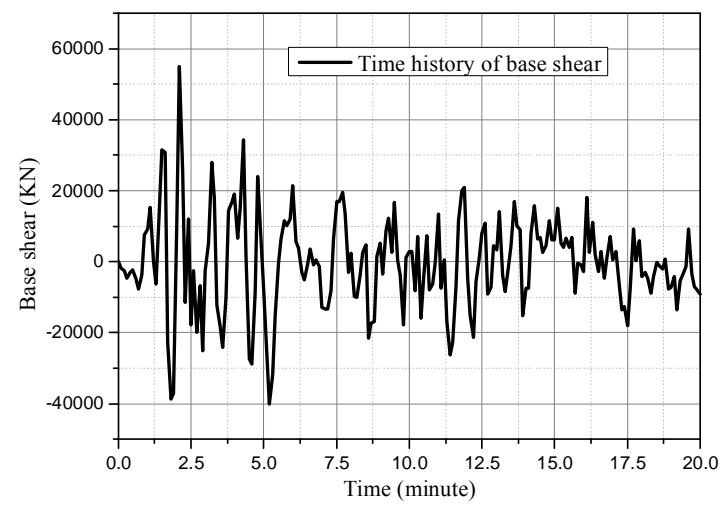

Figure 4 Time history of base shear

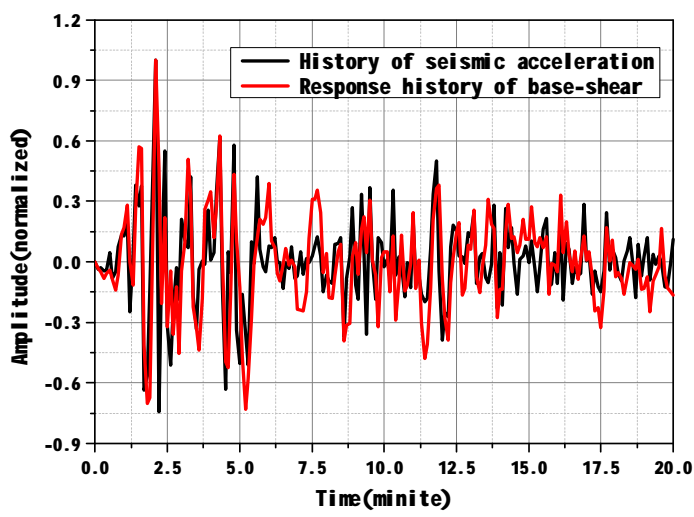

Figure 5 Normalization of the seismic input and response 


\section{$\triangle$ ATLANTIS \\ PRESS}

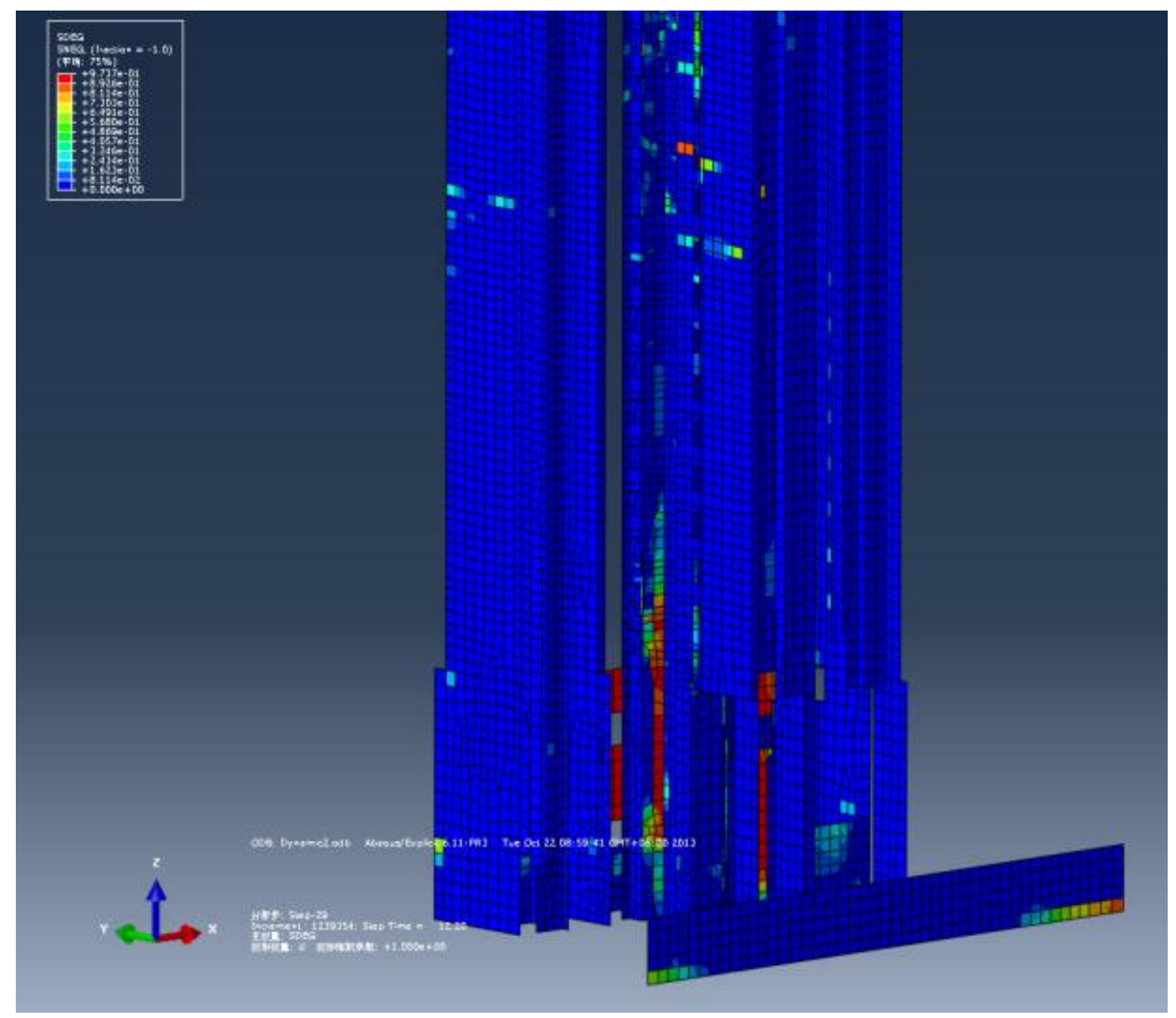

Figure 6 The stiffness degradation of walls 


\section{$\triangle$ ATLANTIS}
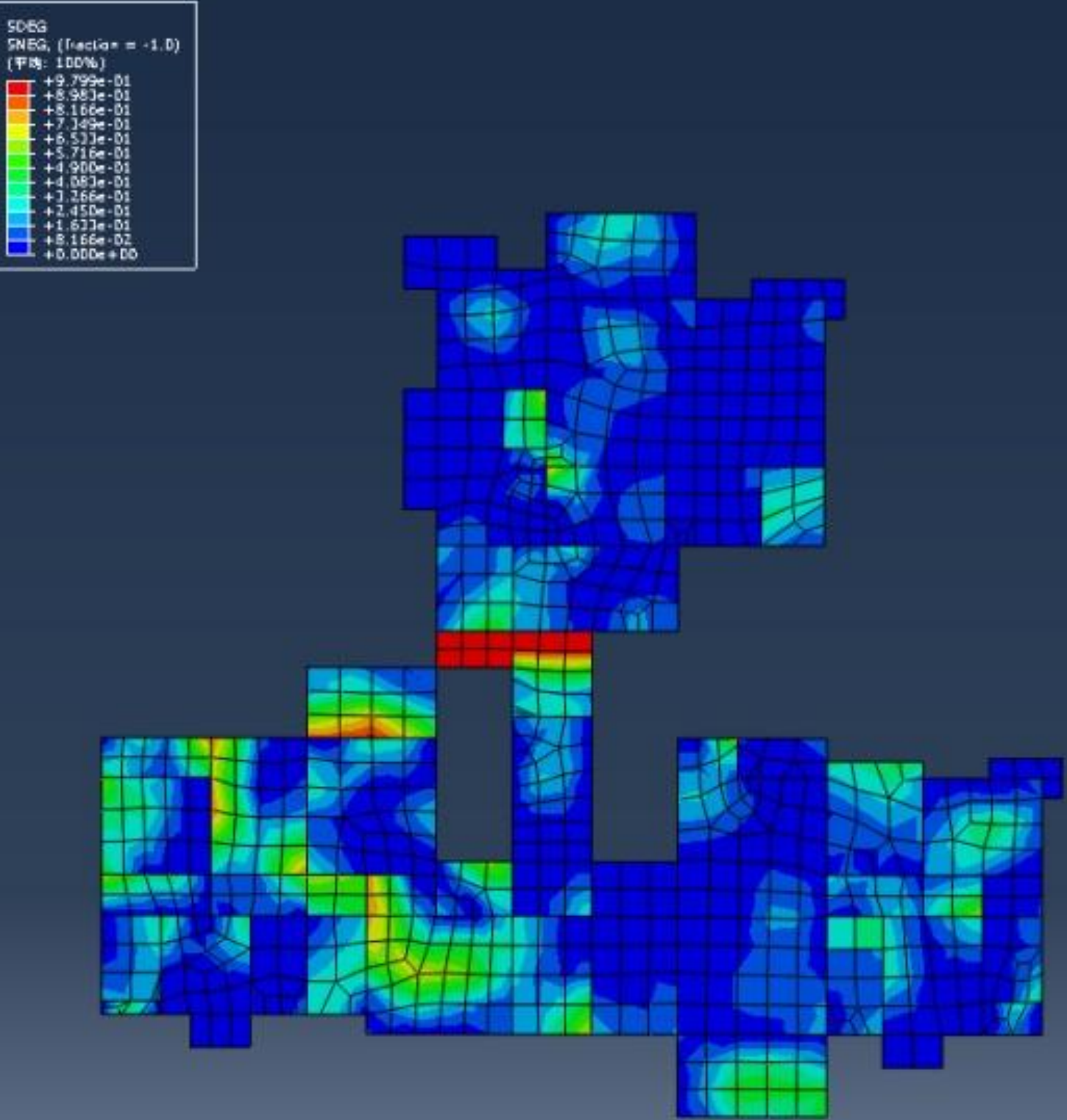

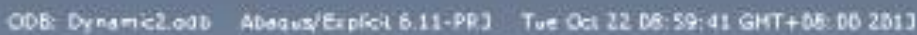

hits: Siep-29

Sovement 127935d: Slep Tune = 12.20

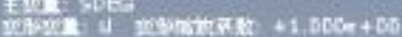

Figure 7 The stiffness degradation of slabs 


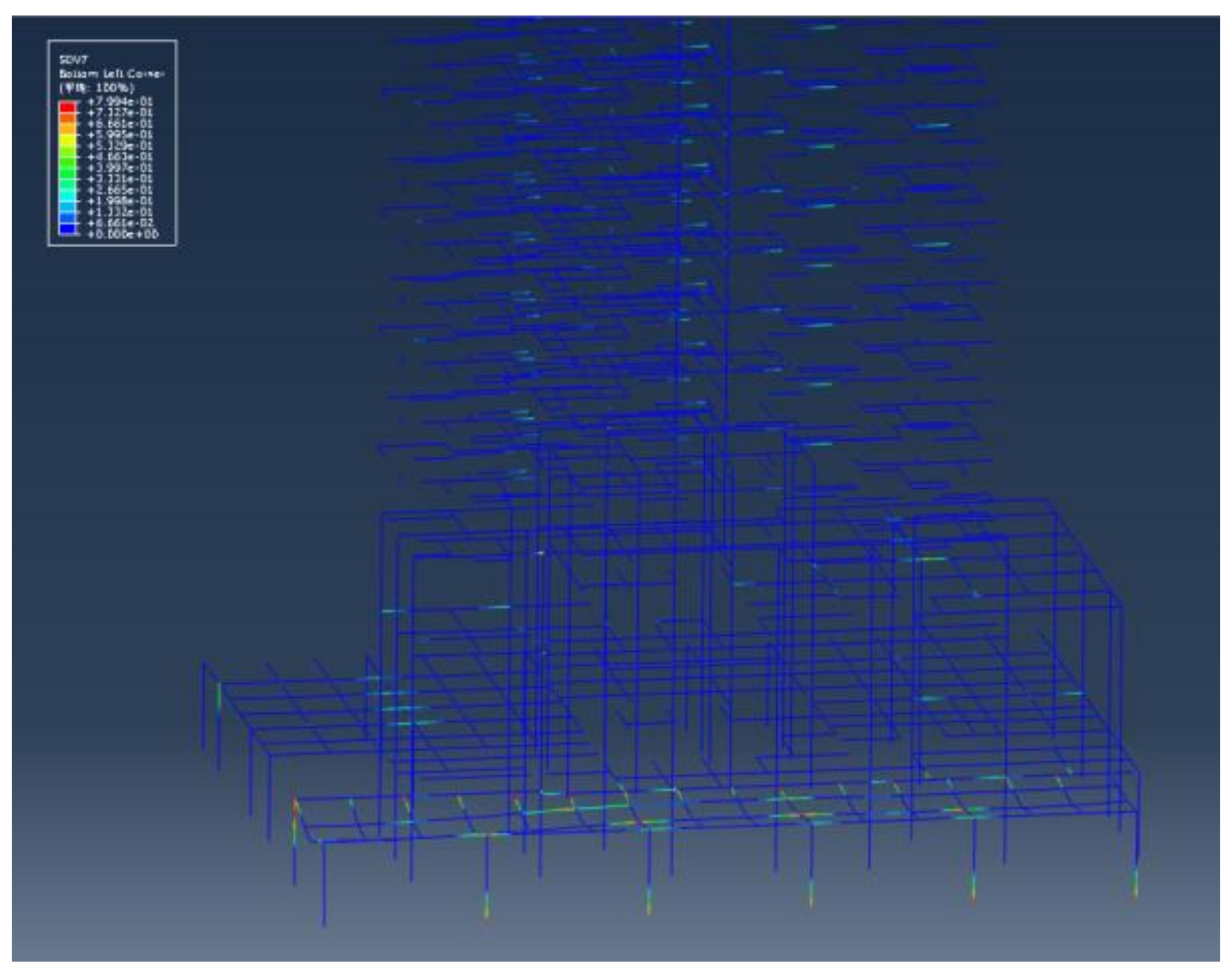

Figure 8 The stiffness degradation of frames

\section{Conclusions}

The application with Abaqus for the structural simulation system, an integrated simulation system for building structures, is presented in this paper. It is aimed to provide dynamic elastic-plastic analysis for reinforced concrete structures. There are two key points are emphasized in this paper: (1) the constitutive model for reinforced concrete, including one-dimensional constitutive and two-dimensional constitutive; (2) the elemental model for reinforced concrete components, including frame component, shear wall and slab. Finally, a high-rise building numerical example is provided to demonstrate the capacity of the structural simulation system.

\section{Reference}

[1] Li Y.G., Duan J. \& Chen X.M. Simulation Analysis and Engineering Examples for Building Structures [M]. Beijing: China Building Industry Press, 2015. (in Chinese)

[2] Duan J., Chen X.M. \& Li Y.G. A Quadrilateral Meshing Method for Shear-Wall Structures [J]. Applied Mechanics and Materials. 2014, 638-640: 9-14.

[3] Duan J., Chen X.M., Qi H. \& Li Y.G. Boundary-Constraint Meshing Based on Paving Method [J]. Applied Mechanics and Materials. 2014, 627: 262-267.

[4] Duan J., Chen X.M., Qi H. \& Li Y.G. An Automatic FE Model Generation System Used for ISSS [C]. Proceedings of Civil Engineering and Urban Planning III. Landon, UK: Taylor \& Francis Group. 2014: 29-32. 
[5] Mander J.B., Priestly M.J.N. \& Park R. Theoretical Stress-Strain Model for Confined Concrete [J]. ASCE, Journal of Structural Division. 1988, 114(8): 1804-1826.

[6] GB-50010-2010. Code for Design of concrete structures [S]. Beijing, China: China Architecture \& Building Press, 2011. (in Chinese)

[7] Abaqus 6.13 Theory Manual. Providence [R]. RI, USA: Dassault Systèmes Simulia Corp, 2013. 